\title{
SURYA ABDIMAS
}

Vol. 5 No. 1 (2021) pp. 28-32

Available online at: http://jurnal.umpwr.ac.id/index.php/abdimas/index

p-ISSN: $\underline{2580-3492}$ e-ISSN: 2581-0162

\section{Pelatihan Pengelolaan Keuangan Keluarga di Masa Pandemi Covid-19 Bagi Ibu-ibu PKK RW. 06 Kelurahan Gembor Kota Tangerang}

\author{
Ade Onny Siagian $\bowtie$ \\ Universitas Bina Sarana Informatika \\ Jl. Kramat Raya No.98Kwitang, Kec. Senen, Kota Jakarta Pusat, 10450, Indonesia \\ | ade.aoy@bsi.ac.id $\bigotimes$ | DOI: https://doi.org/10.37729/abdimas.vi.872 |
}

\begin{abstract}
Abstrak
Pengabdian pada masyarakat ini bertujuan untuk memberikan wawasan pengetahuan tentang pengelolaan keuangan keluarga dimasa Pandemi Covid-19 kepada Ibu-ibu PKK Rw.06 Kelurahan Gembor Kecamatan Priuk di Kota Tangerang, memberikan pengetahuan tentang pengelolaan keuangan guna menciptakan ketahanan keuangan yang cukup didalam keluarga selama pandemi berlangsung, menggunakan metode kualitatif yaitu mengurai data kegiatan dalam bentuk kalimat yang teratur, runtun, logis, tidak tumpang tindih dan efektif. Kegiatan pengabdian masayarakat tersebut yang terukur, terarah dan sistematis. Sasaran kegiatan ini adalah masyarakat Ibu-ibu PKK Rw.06 kelurahan Gembor Kota Tangerang. Permasalahan diselesaikan dengan tiga tahap yaitu perencanaan, pelaksanaan dan evaluasi. Perencanaan dilakukan dengan melakukan survey pendahuluan untuk melihat kondisi di lapangan mengenai perkembangan masyarakat yang terdampak covid-19. Pelaksanaan dilakukan dengan pelatihan menggunakan metode ceramah yaitu dengan teknik presentasi dilanjutkan diskusi sesi tanya jawab sebagai bentuk kegiatan workshop pelatihan pengelolaan keuangan keluarga. Kegiatan tersebut dilakukan secara online melalui aplikasi Zoom Meeting dikarenakan adanya pandemi covid-19. Evaluasi kegiatan dilakukan dengan mengumpulkan dan menyimpulkan data dari masing-masing tahapan kegiatan. Hasil kegiatan pelatihan menunjukan tingkat keberhasilan dengan indikasi adanya kesesuaian materi dengan kebutuhan Ibu-ibu PKK, adanya tanggapan positif dari peserta dan sebagian besar (85\%) peserta telah memahami konsep anggaran pengelolaan keuangan keluarga yang dapat diimplementasikan didalam keluarganya masing masing.
\end{abstract}

Kata Kunci: Pelatihan, Pengelolaan Keuangan Keluarga, Ibu-ibu PKK

$\begin{array}{ll}\text { (c) (i) (8) } & \text { This work is licensed under a Creative Commons Attribution-NonCommercial } 4.0 \\ \text { International License }\end{array}$

\section{Pendahuluan}

Posyandu memegang peranan penting dalam kehidupan masyarakat terutama ibu-ibu PKK RW 06 Kelurahan Gembor Kecamatan Priuk Kota Tangerang memiliki potensi dalam mengelola keuangan keluarga tersebut agar bisa menjadi ketahanan keluarga yang mandiri dimasa pandemi Covid-19. Hal ini dibuktikan dengan mulai tingginya pengangguran dan sumber pendapatan pada masyarakat dan masing masing keluarga yang terdampak pandemi Covid-19 (Wibawa \& Wihartanti, 2018). Terjadinya pandemi Covid-19 membuat banyak aspek yang berpengaruh terhadap defisit anggaran karena menurunnya ekonomi negara. Tingginya pengangguran membuat berkurangnya daya beli dan menurunnya pendapatan rata-rata masyarakat. Pengelolaan keuangan selama Pandemi Covid-19 sangat penting untuk dibuat agar tercukupinya seluruh kebutuhan mendasar dalam keluarga (Rahyu et al., 2019). Keluarga sebagai kelompok terkecil dalam masyarakat harus memiliki ketahanan keuangan yang cukup selama pandemi berlangsung. Peran ibu dalam keluarga memiliki kewajiban dalama rangka membuat pengelolaan keuangan keluarga sehingga diharapkan tidak terjadi kekurangan atau defisit keuangan (Hapsari \& Surya, 2018). Maka sebagai dasar tersebut, kami dari program studi 
Akuntansi Fakultas Ekonomi \& Bisnis Universitas Bina Sarana Informatika ingin memberikan kontribusi dalam Pengabdian Masyaratkat sebagai bentuk Tridarma Pendidikan berupa pelatihan dengan tema pengelolaan keuangan keluarga di masa pandemi Covid-19 bagi ibu-ibu PKK RW.06 kel. Gembor, kecamatan Periuk, kota Tangerang.

PKK atau Pemberdayaan Kesejahteraan Keluarga sebagai salah satu organisasi masyarakat yang tumbuh dari bawah dengan wanita sebagai penggeraknya mempunyai peranan strategis dalam pencapaian tujuan pembangunan nasional. Sejak dicanangkan Tahun 1984 berdasarkan Keputusan Menteri Dalam Negeri No. 28 Tahun 1984 hingga kini PKK telah memberikan kontribusi yang nyata bagi keberhasilan $\mathrm{KB}$, sehingga program untuk menekan angka pertumbuhan penduduk dapat tercapai. Demikian juga peranan PKK dalam mewujudkan keluarga sehat sejahtera melalui Posyandu, PMT, UPGK, Imunisasi, dan lain-lain telah nyata hasilnya (Rantung et al., 2018). Di bidang pembinaan gotong royong, mengembangkan kehidupan berkoperasi dan perencanaan sehat walaupun belum maksimal sudah dapat terasa geliatnya dengan adanya pertemuan rutin PKK tiap bulan. Didalam pertemuan tersebut terdapat kegiatan menabung, pendidikan, siraman rohani dan sebagainya (Angelia E, 2017).

Namun, ke depan PKK harus dapat merubah paradigma lama yang kadang menjemukan. Kegiatan-kegiatan yang terkesan bersifat otoritas, sampai ke bawah kurang memberdayakan potensi masyarakat. Karena itu, sesuai tuntutan zaman perlu adanya paradigma baru. PKK di masa depan hendaknya lebih kooperatif, demokratif, memberdayakan keluarga untuk meningkatkan kesejahteraan menuju terwujudnya tujuan gerakan PKK (Onny Siagian, 2020). Yakni terwujudnya keluarga yang beriman dan bertaqwa, berbudi luhur, sehat sejahtera, maju dan mandiri, memiliki kesadaran dan keadilan gender, serta kesadaran hukum dan lingkungan. Untuk itu ibu-ibu PKK harus membaca agar pintar. Ibu PKK harus mempunyai rumah belajar guna meningkatkan kemampuan dan ketrampilan. Dengan meningkatnya minat baca bagi ibu-ibu PKK, anak-anak dan remaja maka meningkat pula SDM masyarakat. Dengan SDM yang tinggi, wanita / ibu-ibu menjadi mandiri, demokratif, partisipatif dan sadar hukum. Termasuk sadar akan perannya sebagai pendidik yang utama dan pertama dalam keluarga yang wajib membina anak dan generasi muda menyongsong masa depan yang penuh tantangan (Partisipasi Perempuan Dalam Implementasi Kebijakan Pengelolahan Program Keluarga dan Masyarakat Sejahtera, 2013).

Berdasarkan latar belakang permasalahan tersebut, pengabdian kepada masyarakat tentang pelatihan pengelolaan keuangan keluarga di masa pandemi Covid-19 bagi ibu-ibu PKK Rw.06 kelurahan Gembor kecamatan Priuk kota Tangerang menjadi hal penting untuk dilakukan. Kami mencoba untuk melakukan pelatihan pengelolaan keuangan keluarga dimasa pandemi Covid-19 dengan harapan ibu-ibu PKK bisa menggunakan dan mengelola Anggaran Keuangan Keluarga (Dwiastanti, 2018) dan (Suprianto Suprianto, Sitti Hardiyanti Arhas, 2020).

\section{Metode}

Metode kegiatan pengabdian kepada masyarakat ini adalah pelatihan tentang pengelolaan keuangan keluarga dimasa Pandemi Covid -19 bagi Ibu-ibu PKK (Ade Onny Siagian, 2020). Selain itu dijelaskan pula tentang proses pengelolaan pembukuan keuangan keluarga sehingga diharapkan tidak terjadi kekuarangan atau defisit keuangan. Peserta pelatihan mengunakan metode ceramah dengan tehnik presentasi materi dilanjutkan dengan diskusi. Metode ceramah dengan teknik presentasi menggunakan media virtual online berbasis aplikasi zoom meeting dikarenakan kondisi pandemi Covid-19 dan diberlakukannya PSBB (Pembatasan Sosial Berskala Besar) di kota Tangerang.

Kegiatan ini merupakan rangkaian kegiatan pengabdian kepada masyarakat yang diselenggarakan atas hibah internal dari Universitas Bina Sarana Informatika. Kegiatan pengabdian kepada masyarakat ini dilaksanakan tanggal 26 September 2020, pukul 08.00-12.00 Wib. Pengabdian bertempat di lakukan secara Online Zoom Meeting Joint https://us02web.zoom.us/j/89578186170?pwd=VEhkQng5WWUw VTlzVnNnT1RxMnRxZz09, Meeting ID: 8957818 6170, Passcode: ubsistmik. Mitra/subjek pengabdian ini adalah masyarakat peserta ibu - ibu PKK RW.06, Kelurahan Gembor, Kecamatan Periuk, Kota Tangerang. 


\section{Hasil dan Pembahasan}

Pelaksanaan pengabdian ini diawali dengan perkenalan dan maksud dari tujuan melakukan pengabdian kemudian memberikan pengetahuan tentang pentingnya pengelolaan keuangan keluarga. Adapun hasil dari pengabdian ini yaitu :

\subsection{Temuan dan relevansi dengan penelitian terdahulu}

Temuan yang didapatkan dari kegiatan pengabdian ini adalah Masyarakat Ibu-ibu PKK RW.06 Kota Tangerang, tepatnya dalam pengabdian ini adalah berada di daerah pemukiman padat penduduk di jl. raya total persada, kel gembor, kecamatan priuk kota tangerang, berikut adalah lokasi dari Posyandu Delima Putih, belum memiliki pengetahuan tentang pengeloaan keuangan keluarga.

\subsection{Kontribusi Program Pengabdian Kepada Masyarakat}

Program kegiatan pengabdian masyarakat dibagi ke dalam tiga tahapan yaitu: (1) Perencanaan Kegiatan. Dalam tahap ini kelompok pengabdi melakukan survei pendahuluan untuk melihat kondisi kemampuan ibu-ibu PKK harus dapat merubah paradigma lama yang kadang menjemukan. Dilakukan pula pencarian permasalahan yang dihadapi oleh ibu-ibu PKK dalam pelatihan pengelolaan keuangan keluarga . (2) Pelaksanaan Kegiatan. Tahap ini pengabdi melakukan kegiatan pengembangan pengetahuan tentang pengelolaan keuangan keluarga karena wanita sebgai penggerak dan mempunyai peranan strategis dalam mengatur keuangan keluarga. (3) Evaluasi Kegiatan. Tahap terakhir dilakukan evaluasi atas hasil pencapaian peserta pelatihan. Evaluasi dilakukan dengan mengumpulkan data yang diperoleh dari kegiatan pelatihan pengelolaan keuangan. Data diambil dengan menyimpulkan pemahaman peserta pelatihan tentang pengeloaan keuangan keluarga diberikan materi yang disampaikan dengan metode ceramah dan dilanjutkan dengan sesi tanya jawab.atau diskusi.

Indikator ketercapaian tujuan pengabdian adalah $85 \%$ ibu-ibu PKK dapat memahami tentang pengelolaan keuangan keluarga. Pelaksanaan kegiatan ini dikemas menggunakan pendekatan online workshop dengan metode ceramah, diskusi dan tanya jawab. Adapun langkah-langkah dalam pelaksanaan kegiatan yaitu: (1) Peserta pelatihan diberikan materi tentang pengelolaan keuangan keluarga. (2) Peserta diberikan kesempatan untuk melakukan diskusi materi yang telah diberikan. (3) Peserta diberikan penjelasan tentang keuangan keluarga. (4) Peserta diberikan kesempatan untuk berdiskusi tentang hambatan dalam pengeloalan keuangan keluarga. (5) Hasil yang telah dibuat kemudian dikumpulkan melalui email tutor untuk diberikan masukan dan perbaikan berkelanjutan.

Program pengabdian kepada masyarakat yang dilakukan dengan pelatihan ini memberikan kontribusi penting kepada masyarakat terutama ibu-ibu PKK, yaitu dengan memberikan pengetahuan tentang pentingnya pengeloaan keuangan keluarga dimasa pandemi covid -19. Melalui pelatihan ini diharapkan masyarakat memahami pentingnya pengelolaan keluarga agar tercukupinya seluruh kebutuhan mendasar dalam keluarga. Selain itu masyarakat memiliki kesadaran untuk ketahanan keuangan yang cukup selama pandemi berlangsung. Jadi diharapkan tidak terjadi kekurangan atau defisit keuangan. Maka sebagai dasar tersebut, kami dari program studi Akuntansi Fakultas Ekonomi \& Bisnis Universitas Bina Sarana Informatika ingin memberikan kontribusi dalam Pengabdian Masyaratkat sebagai bentuk Tridarma Pendidikan berupa pelatihan dengan tema Pengelolaan Keuangan Keluarga di masa Pandemi Covid-19 bagi ibu-ibu PKK RW.06 Kel. Gembor, Kecamatan Periuk, Kota Tangerang.

\subsection{Diskusi dan tanya jawab peserta dengan pemateri}

Pada kegiatan diskusi dan tanya jawab ini membahas tentang pengelolaan keuangan keluarga melalui aplikasi zoom meeting yang dihadiri oleh ibu-ibu PKK Rw.06. Kegiatan diawali dengan pembukaan sekaligus sambutan yang sampaikan oleh ketua PKK PKK RW.06 kelurahan Gembor seperti ditunjukkan pada Gambar 1. 


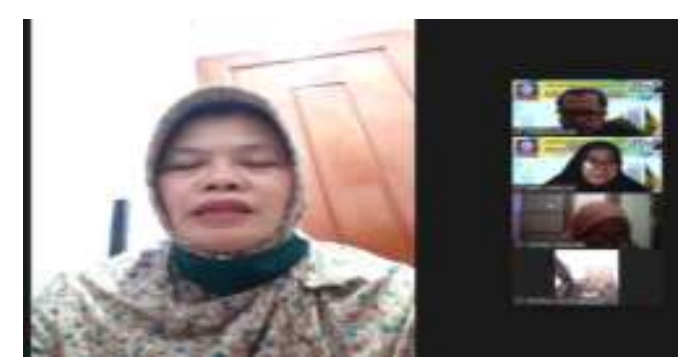

Gambar 1. Sambutan dari Ketua PKK Rw.06 Kelurahan Gembor.

Rangkaian kegiatan penyampaikan materi disajikan menggunakan media zoom meeting, yang diikuti oleh seluruh peserta dengan tertib dan lancar. Materi dalam kegiatan meliputi pengelolaan keuangan keluarga seperti disajikan pada Gambar 2.

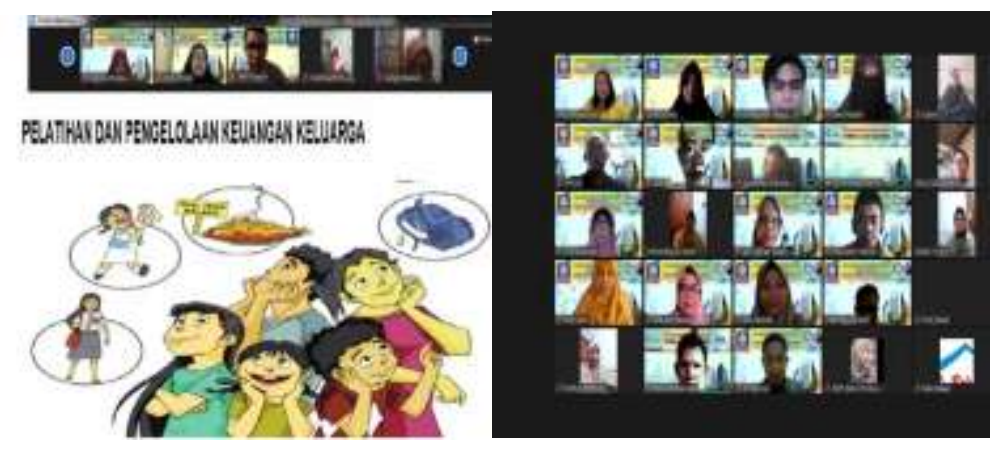

Gambar 2. Penyampaian materi dan tanya jawab terkait pengelolaan keuangan keluarga

Berdasarkan hasil diskusi dan tanya jawab terhadap peserta, disampaikan mekanisme dan proses pengelolaan keuangan keluarga di masyarakat terutama para Ibu-ibu PKK Rw.06 mengingat keluarga sebagai kelompok terkecil dalam masyarakat harus memiliki ketahanan keuangan yang cukup selama pandemi berlangsung. Pada akhir kegiatan, peserta telah memahami dan mengelola tentang keuangan keluarga dalam ketahanan yang cukup selama pandemi covid-19 agar seluruh kebutuhan keluarga dapat tercukupi.

\section{Kesimpulan}

Berdasarkan hasil pengabdian yang telah dilakukan Peran ibu dalam keluarga memiliki kewajiban dalama rangka membuat pengelolaan keuangan keluarga sehingga diharapkan tidak terjadi kekurangan atau defisit keuangan. Maka sebagai dasar tersebut, kami dari program studi Akuntansi Fakultas Ekonomi \& Bisnis Universitas Bina Sarana Informatika ingin memberikan kontribusi dalam Pengabdian Masyaratkat sebagai bentuk Tridarma Pendidikan berupa pelatihan dengan tema Pengelolaan Keuangan Keluarga di masa Pandemi Covid-19 bagi ibu - ibu PKK RW.06 Kel. Gembor, Kecamatan Periuk, Kota Tangerang.

\section{Acknowledgement}

Penulis mengucapkan terima kasih kepada ketua dan ibu - ibu PKK RW.06 Kelurahan Gembor, Kecamatan Periuk, Kota Tangerang sebagai mitra dalam pelaksanaan kegiatan pengabdian kepada masyarakat. 


\section{Daftar Pustaka}

Ade Onny Siagian, N. R. (2020). Pelatihan Pembuatan Buku Besar dan Neraca Saldo Untuk Perusahaan Jasa Di Ppq Nahwa Nur Bogor. Aksara Public, 4(4), 179-188.

Angelia E. (2017). Peranan Perempuan Dalam Pembangunan Masyarakat Desa. Jurnal Politico.

Partisipasi Perempuan Dalam Implementasi Kebijakan Pengelolahan Program Keluarga dan Masyarakat Sejahtera, Governance (2013).

Dwiastanti, A. (2018). Pengetahuan Keuangan Untuk Membentuk Perilaku Keuangan Keluarga (Studi Kasus Pada Ibu Rumah Tangga di Kota Malang). Jurnal Pengembangan Humaniora.

Hapsari, F., \& Surya, S. D. (2018). Efektivitas Kelembagaan Sosial Masyarakat dalam Pemberdayaan Wanita dan Keluarga di Kelurahan Cirasas. JABE (Journal of Applied Business and Economic). https:// doi.org/10.30998/jabe.v4i3.2483

Onny Siagian, A. (2020). Character Building Relasi Dalam Kehidupan Beragama Dan Bersosial (V. Meilinda \& A. S. Wijaya (eds.)). Syntax Computama.

Rahyu, K. D., Kencana, N., \& Isabella, I. (2019). Ideologi State Ibuism Pada Gerakan PKK Di Desa Sumber Agung Kecamatan Keluang Kabupaten Musi Banyuasin Provinsi Sumatera Selatan. Jurnal Pemerintahan Dan ....

RANTUNG, J., MANDEY, J., \& ... (2018). Peranan Pemberdayaan Kesejahteraan Keluarga (Pkk) dalam Menggerakkan Partisipasi Masyarakat Desa (suatu Studi di Desa Ongkau I Kabupaten .... In Jurnal Administrasi ....

metode penelitian kuantitatif, kualitatif,dan R\&D, Alfabeta, cv. __ (2016).

Suprianto Suprianto, Sitti Hardiyanti Arhas, A. O. S. (2020). The Effectiveness of Online Learning Amid the COVID-19 Pandemic. Jurnal Ad'ministrare, 7(2), 321-330.

Wibawa, R. P., \& Wihartanti, L. V. (2018). Peran Perempuan Kepala Keluarga dalam Menciptakan Kesejahteraan Keluarga. Jurnal Ilmu Dan Pendidikan Ekonomi-Sosial. 